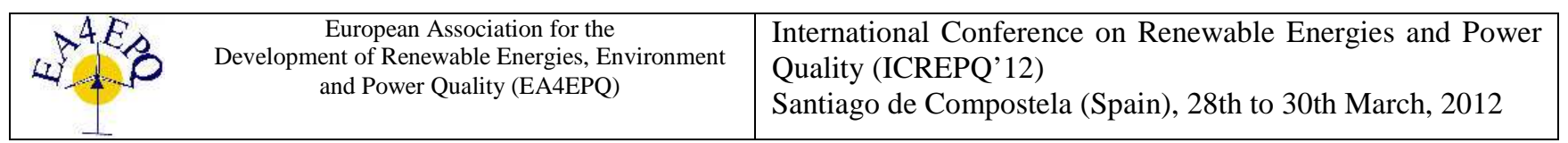

\title{
Greenhouse Gases Emissions by Energy Production and Waste Disposal
}

\author{
Dace Arina, Janis Kalnacs, Alexandr Murashow, Daina Grigale \\ State Research Institute "Institute of Physical Energetics", 21 Aizkraukles Str., Riga, LV-1006, Latvia, Phone +371 \\ 67558782, Fax +371 67550839, \\ e-mail: dace.arina@gmail.com; jkalnacs@edi.lv;
}

\begin{abstract}
Biomass is very important source for energy production in Latvia [1]. Wood biomass - firewood, wood chips and pellets are the main part of biomass, because $54,7 \%$ of the state area is covered by forests. Also other kinds of biomass are playing significant role in the heat and electricity production. Such kinds of biomass are various agricultural and food production residues, livestock breeding buy-products, sewage sludge, organic part of household and industrial wastes, etc. Approximately $1 / 3$ of energy is used for household in Latvia. The significant part of energy is produced in local heating facilities. They by large part of greenhouse gases (GHG) are produced in household. In the same time gases from the municipal waste disposals are also significant source of GHG. The results of measurements and evaluation of GHG emissions from biomass burning in household boilers and municipal solid waste disposals are reported in the present work. The calculations of GHG emissions are conducted by using software and data from Latvian Environment, Geology and Meteorology Centre (LEGMC).
\end{abstract}

\section{Key words}

Renewable energy, greenhouse gases, burning, and municipal bio waste.

\section{Introduction}

There are 795700 households in Latvia. $64.7 \%$ or 1370 573 inhabitants in Latvia are living in dwellings equipped with central heating system, according to data from population census of the year 2000 summarized by Central Statistical Bureau. The gas is mainly used for central heating systems. It is assumed that the rest $35.3 \%$ of inhabitants are living in dwellings equipped with local heating were wood or other biomass are used.

The measurement and evaluation of GHG emissions were made for solid biomass fuels mostly used in Latvia:

1. Firewood,

2. Wood chips,

3. Wood waste,

4. Wood briquettes,

5. Wood pellets,

6. Charcoals.

Determination of emission concentration for above mentioned solid biomass fuels is used for the household sector combustion equipment (small, individual combustion equipment) such as:

1. Central heating boilers,

2. Hot water boilers,
3. Combined (two-functional) central heating and hot water boilers,

4. Room stoves,

5. Economic stoves,

6. Cooking ovens.

The most commonly used burning equipment in Latvia was tested.

Bio waste with low caloricity and high humidity is mainly disposed in a landfill. The gas generated within the waste disposal contains about $60 \% \mathrm{CH}_{4}$ and about $40 \% \mathrm{CO}_{2}$ as well as other easy volatile compounds. The methane gas as an end product of the anaerobic decomposition process is the main GHG with a global warming influence about 21 times over that of $\mathrm{CO}_{2}$ which is used as a reference data for estimation of GHG. Concentration of degradable organic carbon (DOC) which is the main producer of GHG, within definite type of waste is: paper and textiles $40 \%$; waste of gardens and parks as well as other non food decaying waste $17 \%$; food waste 15\%; waste of wood and straw $30 \%$ (excluding lignin). According to the measurements of year 2006-2007 the biodegradable organic part of household waste in average is not exceeding 40-50\% [1].

\section{Measuring Equipment}

Following gas analyzers were used for measuring the concentration of GHG components in flue gases:

1. ECOM-S, Umwelttechnik GmbH, Germany;

2. SWG-200, MRU GmbH , Germany;

3. AIRfair Vario Plus, MRU GmbH, Germany.

If necessary, gas generators were equipped with additional equipment, such as $\mathrm{CO}$ oxidation chamber, flue gases cooling systems, dust filters and others. For integral determination of concentration of individual components in the GHG emissions, Fourier infrared spectrometer IR Prestige-21, Shimadzu, Japan, graduated (calibrated) by the corresponding gases was mainly used.

\section{Measurement Methodology}

In household furnaces and boilers undergoing the testing, there are very minimal opportunities to change the fuel combustion conditions, on which the amount of gas emissions and, in particular - the composition is heavily dependent. 
Therefore to make sure that combustion conditions are defined more properly, they were controlled and stipulated under the individual outputs. The measurement conditions were monitored by gas analyzers and determination of gas component concentrations started only after reaching the stable regime. Gas analysis was done according to standard ISO 10396:1993 requirements. The regime was characterized by the average flue gas temperature and oxygen content.

Carbon monoxide $\mathrm{CO}$, nitrogen oxides NOx and methane $\mathrm{CH}_{4}$ average concentrations were measured 30 minutes after reaching the stable regime. Measuring of GHG components concentrations were made every second and approximated for minute in 30 minutes period. Fig.1.and 2. show examples for result calculation in case of $\mathrm{CO}$.

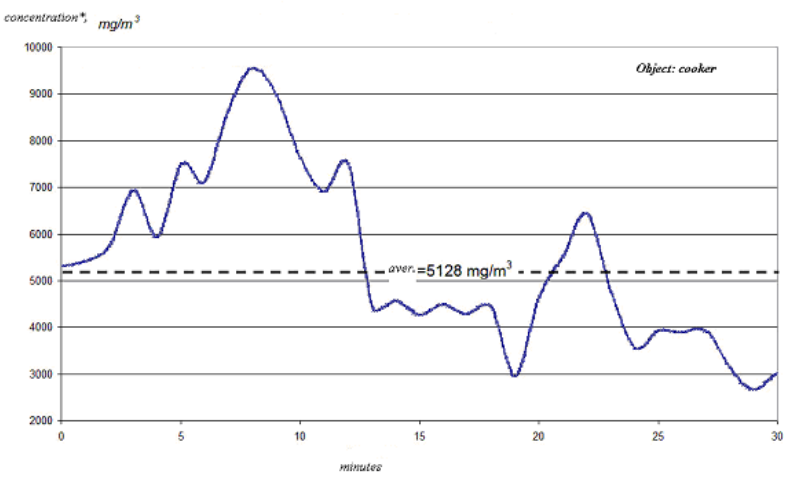

Fig.1. Changes of CO concentration in flue gases for household cookers and room stoves utilizing firewood (* recalculating to normative content of oxygen within flue gas $=6 \%$ ).

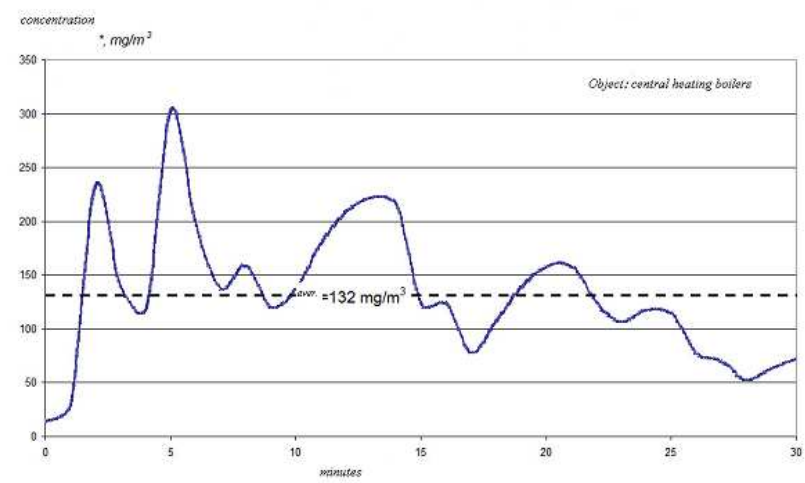

Fig.2. Changes of $\mathrm{CO}$ concentration in flue gases for central heating boilers utilizing wood chips (* recalculating to normative content of oxygen within flue gas $=6 \%$ ).

Parameters of fuels and boilers, used for calculations are aggregated in Table 1 .
Table I.-Parameters of fuels and boilers used for calculations

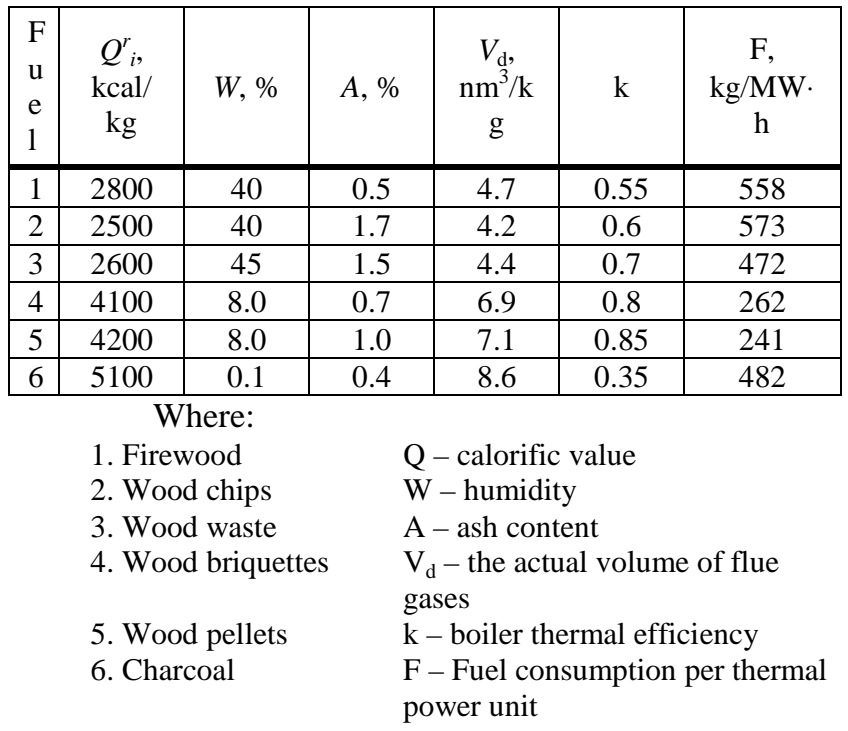

Methane emissions from municipal waste landfills are used for energy production. The use of energy reduced emissions of methane. Figure 3 summarizes the amount of biodegradable organic disposal waste that was assessed by using data bases of Latvian Environment, Geology and Meteorology Centre (LEGMC).

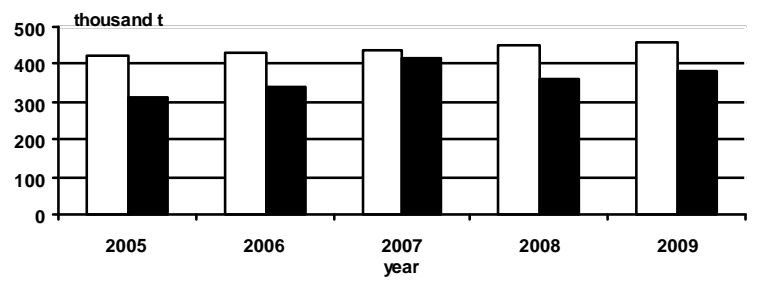

Fig. 3. Planned and disposed amount of biodegradable organic waste from 2005. - 2009. ( $\square$ - planned; $\square-$ disposed).

According to Latvia's Waste Management plan 20062012, $\mathrm{CH}_{4}$ recovery from landfills is one of priorities in waste management. The substantial change of methane emission will be determinable during next decades taking into account that amount of gases emissions will be formed also from organic substances stored during previous years and that amount of biodegradable organic waste to be stored will be reduced gradually according to waste management plans.

\section{Results}

\section{A. Energy Production}

Determinated average values of concentration for different components of GH Gases by combustion of different fuels in the household boilers are collected in Tables $2-4$. 
Table II.- CO concentration ratio of flue gas in $\mathrm{mg} / \mathrm{m}^{3}$

\begin{tabular}{|l|c|c|c|c|c|c|}
\hline \multicolumn{1}{|r|}{ Boiler } & 1 & 2 & 3 & 4 & 5 & 6 \\
\hline Fuel & & & & & & \\
\hline Wirewood & 480 & 353 & 287 & 756 & 577 & 2128 \\
\hline Wood chips & 191 & 153 & 120 & - & - & - \\
\hline Wood waste & - & 453 & - & 566 & 486 & 460 \\
\hline Wood pellets & - & 635 & - & 754 & 835 & - \\
\hline Charcoal & - & - & - & 93 & 98 & - \\
\hline
\end{tabular}

Table III.- NOx concentration ratio of flue gas in $\mathrm{mg} / \mathrm{m}^{3}$

\begin{tabular}{|l|c|c|c|c|c|c|}
\hline Fuel & 1 & 2 & 3 & 4 & 5 & 6 \\
\hline Firewood & 170 & 186 & 121 & 93 & 52 & 72 \\
\hline Wood chips & 159 & 122 & 161 & - & - & - \\
\hline Wood waste & - & 137 & - & 62 & 27 & 39 \\
\hline Wood briquettes & - & - & - & 57 & 37 & 68 \\
\hline Wood pellets & 78 & 175 & - & 88 & 54 & - \\
\hline Charcoal & - & - & - & 46 & 33 & - \\
\hline
\end{tabular}

Table IV.- $\mathrm{CH}_{4}$ concentration ratio of flue gas in $\mathrm{mg} / \mathrm{m}^{3}$ units.

\begin{tabular}{|l|c|c|c|c|c|c|}
\hline Fuel & 1 & 2 & 3 & 4 & 5 & 6 \\
\hline Firewood & 10 & 17 & 21 & 158 & - & - \\
\hline Wood chips & 5 & 12 & 19 & 155 & - & - \\
\hline Wood waste & 11 & 10 & 26 & 162 & - & - \\
\hline Wood briquettes & - & 23 & - & 275 & 270 & 230 \\
\hline Wood pellets & $1300^{*}$ & - & 470 & 270 & - & - \\
\hline Charcoal & - & - & - & 263 & 250 & - \\
\hline
\end{tabular}

Boilers were:

1. Central heating boilers,

2. Hot water boilers,

3. Combined (two-functional) central heating and hot water boilers,

4. Room stoves,

5. Economic stoves,

6. Cooking ovens.

* - The result was obtained for automatic boiler working in the smouldering mode as warm weather conditions determined a small actual power of boiler.

The results of investigations show, that nitric oxides emissions from household combustion facilities are stable and small, also play not significant role for total emissions amount. $\mathrm{N}_{2} \mathrm{O}$ emissions we don't find for all household boilers. $\mathrm{CO}_{2}$ emissions can be excluded, because biomass is $\mathrm{CO}_{2}$ neutral. $\mathrm{CO}$ emissions, if the regime of combustion is stable and air flow is optimal, are also small and can be used mainly as combustion regime quality parameter. It can be assumed that extra emissions by combustion of biomass are mainly as $\mathrm{CH}_{4}$.
According to Latvia national inventory report, 2010 [3] Table 5,

in 2009 residential emissions were $10,41 \mathrm{Gg}$ and from biomass $-10,1 \mathrm{Gg}$. The possibility for elimination is only by using optimal combustion regime.

Table V.- Residential GHG emissions, total (Gg)

\begin{tabular}{|l|l|l|l|}
\hline Year & 2007 & 2008 & 2009 \\
\hline $\mathrm{CO}_{2}$ & 421,53 & 424,46 & 397,42 \\
\hline $\mathrm{CH}_{4}$ & 9,44 & 9,36 & 10,41 \\
\hline $\mathrm{N}_{2} \mathrm{O}$ & 0,12 & 0,12 & 0,14 \\
\hline
\end{tabular}

\section{B. Emissions from waste disposal}

Figure 4 shows assessment of total emissions from waste in solid waste disposing sites and the broadcast till the year 2020 calculated by LEGMC programmes according to United Nations Recommendations (IPCC Guidelines for National Greenhouse Gas Inventories, 1996) [4].

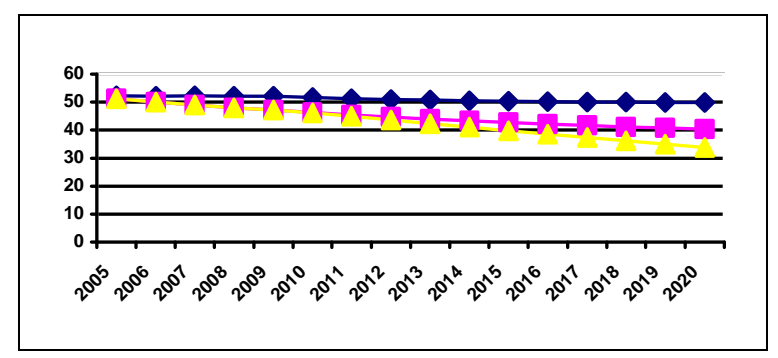

Fig.4. Broadcast of methane gas emission $(\mathrm{Gg})$ from biodegradable organic waste disposed from $2005-2020(\diamond$ amount of created disposed organic; - amount of practically disposed organic; $\Delta$ disposed according to Waste Management Plan).

The aim of investigations is to determine the concentration of organic carbon (DOC) for waste disposed in landfill. There where $568517 \mathrm{t}$ of unsorted household waste disposed in landfills in Latvia in the year 2010 [3]. Figure 5 shows the average composition of municipal solid waste within three inspected landfills in Latvia.

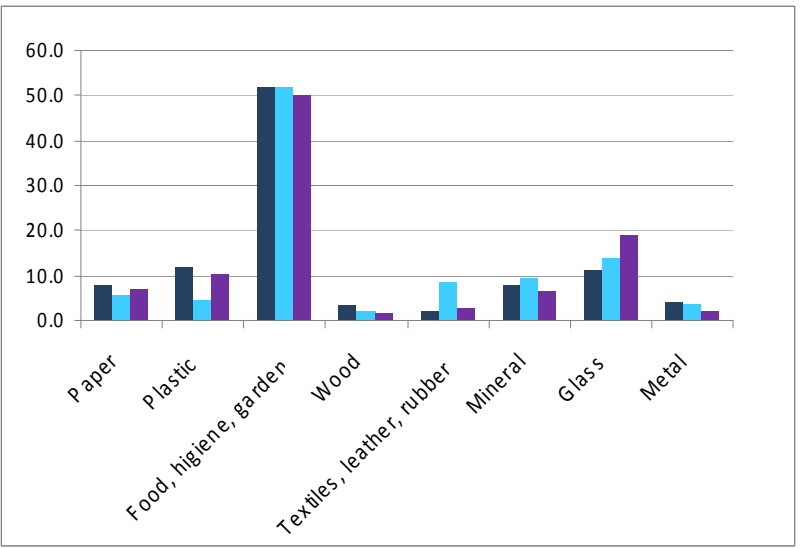

Fig.5. The average composition of municipal solid waste within inspected landfills in Liepaja, Ventspils and Pieriga regions ( \% of dry mass) $\square$ - Ventspils region; - - Liepaja region; $\square$ Pieriga region. 
There are approximately $60 \%$ of biodegradable wastes including kitchen, green, paper, wood, textiles, and leather waste.

According to household waste composition study in 2007 the composition of unsorted household waste collected from inhabitants is: biodegradable waste $35.7 \%$, garden waste $4.5 \%$, paper and cardboard $24.9 \%$, plastic $18.8 \%$, glass $5.6 \%$, metal packing $0.9 \%$, non-combustible (ash, soil, mineral waste) $6.8 \%$, other $2.8 \%$ [5]. To compare the content of disposed waste and produced by households it can be assumed that the volume of biodegradable waste in a landfill is formed by $36 \%$ of household and $24 \%$ of commercial waste.

According the measurements of total carbon was calculated the content of degradable organic carbon (\% of mass): in Ventspils region - $11.55 \%$; in Liepaja region 14.73; in Pieriga region $-19.74 \%$. As it can be reflected by our measurements, DOC differs depending from region to region in Latvia. It can be explained by differences of national economy, welfare and other factors within regions. The present situation is represented by DOC data from landfills with amount of $19 \%$ as an average DOC for Latvia taking into account amount of disposed waste.

\section{Conclusions}

1. $\mathrm{CO}, \mathrm{NOx}$ and $\mathrm{CH}_{4}$ emissions by biomass combustion in small capacity furnaces are more dependent from boiler operation regime, but not from biomass form.

2. $\mathrm{CH}_{4}$ emissions have been detected for practically all furnaces and can be assessed as minor, but precise result can be obtained only for the particular furnace in the particular circumstances.
3. Largest SEG reduction could be obtained within production of compost and biogas by converting biodegradable waste of household and service sector. The paper, plastic and textile from unsorted waste can be used for solid recovered fuel production after bio-mechanical pre-treatment.

4. In order to use in the emission calculations 2006 IPCC Guidelines for National Greenhouse Gas Inventories, it is necessary to provide the experimental survey in the waste landfills to identification the biodegradable waste amount, content and to detect the degradable organic carbon content in the waste mass.

5. Relative contribution of every single landfill in production of common DOC volumes must be taken into account within calculations and prognosis of Greenhouse Gas Emissions.

\section{Acknowledgement}

Acknowledgement to the European Social Fund (ESF) agreement No: 2009/0180/1DP/1.1.2.1.2/09/IPIA/VIAA/017 for the doctoral research grant award to the first author.

\section{References}

[1] J. Kalnacs, R. Bendere, D. Arina, V. Dubrovskis, Agricultural By-products and Waste Biomass Energy Potential in Latvia 2005-2009; Renewable Energy \& Power Quality Journal, N.9, 12th May 2011, first page 285

[2] V. Čudeckis, R. Bendere, The estimation of the emission of greenhouse gasses by the treatment of bio waste or their disposal in sanitary landfills, in Proc. ISWA, 2011.

[3] Latvia national inventory report, 2010.

[4] Data of Latvian Environment, Geology and Meteorology Centre (LEGMC): http://www.meteo.lv/public/datu bazes.html

[5] Interreg III B Project - Regional Cooperation in Waste Management (RECO), partner: the Waste Management Association of Latvia, 2007. 